$\xi=-1$

\title{
The Model for Thais Physician Competency Development Based on Focus Discussion Group (FDG): A Review
}

\author{
Chutima Pingmuang ${ }^{1 *}$, Somboon Sirisunhirun², Mohd Ekhwan Toriman ${ }^{3}$ \\ ${ }^{I}$ Faculty of Social Sciences and Humanities, Mahidol University, Nakhon Pathom, Thailand \\ ${ }^{2}$ Faculty of Social Science and Humanities, Mahidol University, Bangkok, Thailand \\ ${ }^{3}$ School of Social Development and Environmental Studies, Faculty of Social Science and Humanities, Universiti Kebangsaan Malaysia, \\ 43600 UKM Bangi, Selangor, Malaysia. \\ *Corresponding author E-mail: chutima.pingmuang@gmail.com
}

\begin{abstract}
Current changes and priorities in the country regarding population patterns and health care programs will require reforms in older health care and the increasing incidence of chronic diseases. In this study, the data was collected using with a systematic-purposive sampling using the snowball Delphi technique, key informants comprising 21 experts were selected from the Medical Council of Thailand, the Medical Association of Thailand and Health Systems Research Institute (HSRI). The tools used in this research include in-depth interview, the Likert scale with five-level Likert items for measuring the dispersion and congruence of consensus, and the Likert scale with three-level Likert items for content validity which is analyzed using the items of objectives congruence (IOC), the median (MD) and the quartile deviation (QD). The results show to be both valid and reliable for measuring physicians' competency in Thailand. The results of the competency-based instrument can be used as of to be the healthcare public policy to encourage and guide regarding healthcare agencies to modify their competency according to the evaluation criteria, and also cultivate physicians with strong knowledge and skills, innovation and redesign the curriculum in medical schools inevitably. Overall, the level of physician's desirable competency will be increased in Thailand.
\end{abstract}

Keywords: Thailand; Physicians; Competency; Development; Healthcare.

\section{Introduction}

Generally speaking, ongoing changes in demographics and health care financing will require reforms in health care delivery. An aging population and increasing rates of chronic disease, advances in medical science, health information technology's ability to make care safer and more efficient, skyrocketing costs, and the impact of the Patient Protection and Affordable Care Act (ACA) will require a rethinking of how care is delivered [1]. Apart from this, healthcare quality has yet to meet the aims of medical community with respect to safety, effectiveness, patient-centeredness, efficiency, timeliness and equity. No professional curricula adequately prepare future healthcare practitioners-including medical laboratory science professionals-with all competencies necessary to deliver quality healthcare. Practicing evidence-based medicine, focusing on quality improvement, using information technology, delivering patient-centered care and working as part of interdisciplinary teams are identified by the IOM as the five core competencies that every healthcare practitioner needs to effectively provide healthcare [2].

As for Thailand as same as situation of an oversea facing in term of healthcare mentioned above, apart from that, there is also evidence showing that Thai medical personnel are now facing a critical issue caused by litigation. The statistics of medical cases from 1995 - 2015 comprises 241 civil cases, 36 criminal cases and two administrative court cases. There are 44 civil cases and consumer cases in the court (the total value of all lawsuits is approximately
2.873 billion baht, of which 14 cases are in the Court of First Instance, 10 cases in the Appeal Court, and 20 cases in the Supreme Court). The total number of consumer cases from 23 August 2008 to 30 November 2015 is 133 cases, of which 100 cases were settled at mediation. (The total value of lawsuits is $874,923,514.83$ baht. Money used in the mediation of 100 cases is $20,495,000$ baht) [3].

According to a definition by the World Health Organization (WHO), efficient treatment is not merely providing the treatment of diseases or illnesses, but also creating patients' strength physically, mentally and socially. Such a key, therefore, are medical doctors needed to be adjust themselves by increasing their competencies in medical treatment in all dimensions. Based on this, thus, it is lead to questions to determine "a model for Thai physician competency development" on the grounds that among government officials who implement the government policy, medical personnel, particularly physicians in the public sector, are regarded the most important healthcare service provider [4]. It is therefore necessary that they possess appropriate competency for diagnosing and providing medical treatment. With appropriate competencies, these physicians will be able to provide prompt treatments, reduce risks to error, as well as contribute to effective referral of patients to specialists [5].

To complete such above challenge questions, the research had been design by delineating inevitable concerning literature review and related researches to comprehend the development of the physician competency and related factors from an international scheme. The aim of this paper was to find out the desirable model for the Thai physician competency development. After founding 
the cleared cut an appropriated physician core competency, such attributions had been discussed and refining by the expert senior as of to be the member of medical community.

\section{Methodology}

The Delphi technique was the main method for this study through applied to the selection of experts for determining variables and variable clustering in the first place. The samples who act as the experts in this study all have educational qualifications, key medical position and working experiences that are highly reliable and widely recognized in the society and among the medical profession. They are able to precisely provide key information about a model for Thai physician competency development, both in terms of academy and reality. Therefore, each of the samples is regarded as a person who is truly experienced in the medical profession.

A total of three experts with deep knowledge of Thai medical competencies were selected comprising the President of the Medical Council of Thailand, the President of the Medical Association of Thailand, and the Executive Director of Health Systems Research Institute (HSRI). Each of the three experts was tasked to further recommend a list of 15 qualified experts, totally 45 experts were recommended at this stage. Then, each of these 45 experts was tasked to recommend another 30 qualified experts. Therefore, a total number of selected experts were 1,350 with some duplication. This stage is systematic-purposive sampling of key informants with an objective to define content validity based on the index of item-objective congruence (IOC) measure. Such key informants include the President of the Medical Council, the President of the Medical Association, and the Executive Director of Health Systems Research Institute (HSRI), totally three persons. They were selected since they have long experiences on Thai physician competency development and are widely acknowledged among the medical profession.

The research had conducted during August 2015-May 2017. In addition, key Informants for Focus Group include: 1) 21 experts for this study 2) The committee of the Medical Association. The researcher was allowed to present the study findings in their monthly meetings. As for the research tools, there were as; 1) Indepth interviews with 21 experts who are key informants. 2) The Likert scale with five-level Likert items for measuring the dispersion and congruence of the experts' opinions using the Delphi technique. There is a statistical medium that measures the trend to the middle, namely the median. The base values and the range of range between quarter tiles are used to determine the resolution in accordance with the majority of sound.

The criteria base value is not less than 3.5 , and the range of quarter is not over 1.5, and an inspection of the distribution coefficient resulting from standard deviation is divided into average. The spread of the distribution coefficient is greater than zero but not exceeding 0.5 will be able to terminate the research with Delphi technique and 3) The Likert scale with three-level Likert items (1= Slightly appropriate $/ 2=$ Appropriate $/ 3=$ Absolutely appropriate) for content validity. Different data analysis techniques suitable for each step of researches were administered in this study namely percentage, median (MD), quartile deviation (QD), and content analysis based on the items of objectives congruence (IOC). Then, the statistics obtained were processed and only elements with the value of I.O.C above 0.5 were kept, while any elements below 0.5 I.O.C value were removed.

The meeting (Focus Group Discussion) allowed the researcher to present all of the research finding, as well as present the elements derived from this study one by one which were widely discussed in the meeting. Finally, the meeting agreed with almost all elements researcher founded, except one that the meeting resolved a revision in some part of it.

\subsection{Data Analysis}

Documentary review was employed to delineate information about the current problems that affect the work performance of Thai physicians, the element of desirable Thai medical competencies, and the model for Thai physician competency development. There are also the interviews with experts who are selected by applying a Delphi technique. Prior to developing a model for Thai physician competency development, it is necessary to firstly identify baseline competencies and then seek a way to achieve such base line. Consequently, the results of data analysis are presented in the forms of content and supportive tables. The data analysis is divided into 4 parts as follows:

Part 1: Data about the status of the samples. It was found that the sample were male and female physician with age between $40-79$ years of age in all special field of expert (General Surgery, Neurosurgery, Forensic Medicine, Family Medicine, Otolaryngology, Plastic Surgery, Internal Medicine, Epidemiology, Anatomical Pathology, Obstetrics and Gynecology, Hematology). They had experienced in medical works between $20-59$ years.

Part 2: Analysis of the current problems that affect the work performance of Thai physicians. To analyze the current problems that affect the work performance of Thai physicians, the researcher has drawn from documents, concepts, theories and research works relating to the current problems that affect the work performance of Thai physicians of 21 academia's in order to analyze key words that relate to the current problems that affect the work performance of Thai physicians based on such key word analysis, the current problems that affect the work performance of Thai physicians have been synthesized into the following 17 elements relating to the current problems that affect the work performance of Thai physicians.

Part 3: Analysis of the elements of desirable Thai medical competencies. Literature review integrating with related research had conducted to refine an elements of desirable Thai medical competencies of 21 academia's in order to analyze key words that relate to the elements of desirable Thai medical competencies based on such key word analysis, the elements of desirable Thai medical competencies have been synthesized into the following 25 elements relating to the elements of desirable Thai medical competencies.

Part 4: Analysis of the model for Thai physician competency development. The findings drawn from this study are applied into a model relating to a process for developing Thai physician competency, as shown in following Figure 1. 
(A)

\section{Concepts of a model for Thai physician compe- tency development}

Hypothesis 1: Desirable
Thai medical competen-
cies
Hypothesis 2: Model for
Thai physician competen-
cy development

(B)

\section{Elements based on objectives}

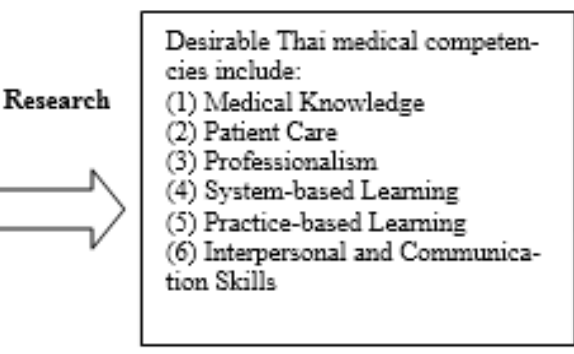

(C)

Propositions

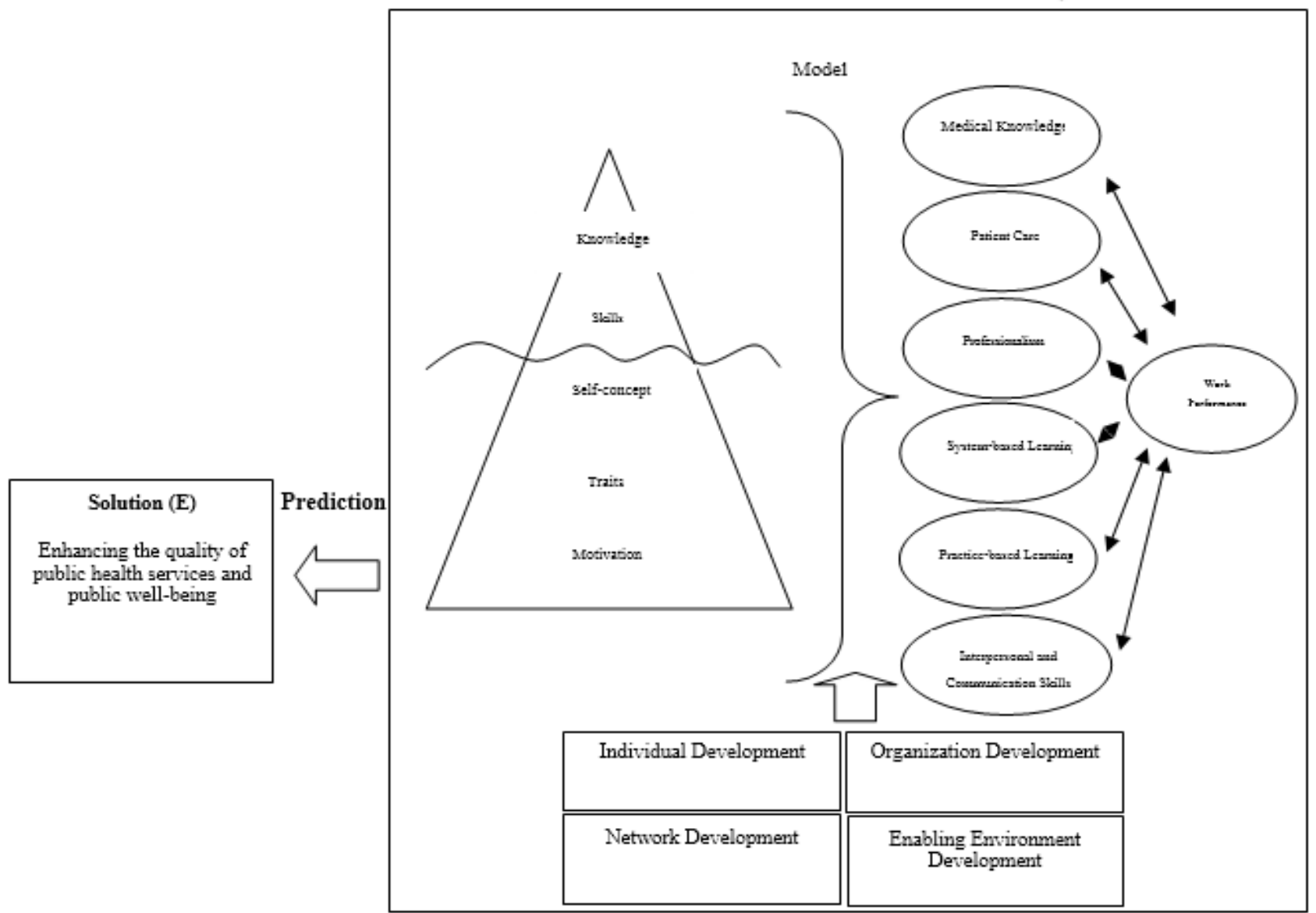

(D)

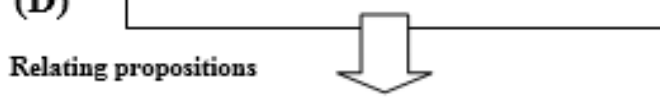

velopment includes:

(1) Individual Development

(2) Organisation Development

(3) Network Development

(4) Enabling Environment Development

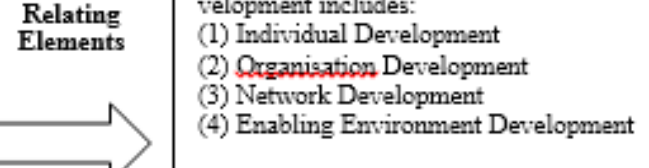

Relating propositions

Fig. 1: The analysis of the model for Thai physician competency development.

\section{Results and Analysis}

\subsection{Current Problems that Affect Work Performance of Thai Physicians}

Based on this study, one of important problem in patient treatment is the lack of basic understanding about illness among the public; hence no effort taken to prevent their sickness and heavy burden placed on physicians who consequently have to take less time to treat other patients with serious illness. Other problems include over-expectation from patients and their relatives, and subsequent litigations.

Primary care physicians or family clinic physicians are viewed as second-class doctors receiving less attention from the state. In fact, family-level practice is crucial since it is where a medical treatment begins. In addition, doctors are not able to use core competencies in several situations, particularly in a hospital's emergency room where treatment is provided in such a hurry manner with restricted conditions and limited medical equipment. There is no process to establish a public healthcare system that widely extends to every region in order to truly seek cooperation from communities $[4,5]$. Apart from this, elderly patients and some types of patients who need to be hospitalized for a long period of time such as patients with paralysis, impose a burden on physicians, making them lose an opportunity to treat other patients.

\subsection{Desirable Thai Medical Competencies}

\subsubsection{Medical Knowledge}

There are two levels of competencies i.e. the first-level competencies for primary care physicians which focus on family medicine, providing a holistic community-based healthcare in which physicians [6], patients and their relatives understand each other like a family; and the higher-level competencies for specialists who need to also have deep academic knowledge such as neurosurgeons and cardiac surgeons. Doctors who have completed specialized train- 
ing as specified by the Medical Council, for example, 3-year training for ophthalmologist and 5-year training for surgeons are considered as already having desirable specialized competencies. Having knowledge and understanding of medical diseases, whether contagious diseases, non-communicable diseases, genetic disorder, environmental diseases, emerging diseases, reemerging disease, which require sufficient knowledge and an ability to control diseases. Doctors need to have knowledge of medical law. Meanwhile doctor must acquire specific skills required for each work [7].

\subsubsection{Patient Care}

Having an intention to become a good doctor since studying in a medical school; having an intention to provide public healthcare without expecting wealth. Doctors must possess accountability, honestly, sacrifice, self-confidence, carefulness, and initiative in their work. The most important desirable medical competency is being a good person thinking of good things and doing well, being moral, and not thinking of self-interest as these are the fundamentals that lead to other competencies [8].

\subsubsection{Professionalism}

Doctors must have the knowledge of management in order to encourage cooperation from co-workers and manage administrative resources to efficiently and effectively generate concrete results. Doctors must have a profound academic knowledge of medical profession included they must show leadership in work and at the same time be a good follower by being rationale and recognizing their roles. Moreover, good governance must be observed in medical practices [9].

\subsubsection{System-Based Learning}

For optimized performance, it is necessary to have teamwork among doctors in various fields, such as internal medicine, obstetrics and gynecology, surgery and pediatrics, so as to provide a holistic and systematic treatment, as well as to create a network of patient service which covers all aspect of treatment. General practitioners must be able to diagnose for referral from primary care to secondary care; for example, in case of diabetes, if there are complications relating to the eyes, referral will be made to an ophthalmologist. An ability to effectively solve immediate problems [10].

\subsubsection{Practice-Based Learning}

Doctors must have a true understanding of the way of living of patients in each region, applying the royal strategy of understanding, outreaching [11] and developing and able to apply innovative technology, be modern and adjust to social changes so that they can carry out their tasks under the government's policy included able to adjust themselves to the social environment.

\subsubsection{Interpersonal and Communication Skills}

Doctors must have the communication skill, both among medical practitioners themselves and with patients in order to make all parties recognize the fact and open their minds to the patient's freedom to choose treatment and cooperate with other professions in order to provide comprehensive services included publicize information about illnesses such as how to prevent illnesses, basic healthcare knowledge so as to lessen doctors' workload [12].

\subsection{The Model for Thai Physician Competency Devel- opment}

\subsubsection{Individual Development}

The key model for competency development is special training, followed by continuing education to learn about both management and medical law so that physicians can use such knowledge to protect themselves. Basic competency development should begin after graduation when physicians are required to undertake medi- cal internship in rural areas for a certain period of time in order to learn the way of life as well as develop their minds while exercising academic training $[13,14]$. Apart from skill development, the process of medical competency development must also include moral development. Furthermore, physicians must be evaluated according to the ethical standards. Fellowships for further education in other countries should be promoted, but only in selective areas that are essential and suitable for Thai society. Medical competency development should promote the knowledge of communication and interpersonal skills.

\subsubsection{Organizational Development}

Capacity building for medical schools should be prioritized. Physician enhancement should start from enhancing doctors who teach in medical schools. Moral and ethical development for physicians should be implemented at the beginning of medical education and should be formulated into a clear strategic plan to be further implemented [15].

An in-depth research on a model for Thai physician competency development should be conducted and summarized the research results to show the clear steps and process for such development. To allow physicians to further their education, it should take into consideration specialized areas required by Thai society. The whole system, including physicians, hospitals, working environments and other relevant medical institutes, should be improved. In addition, Congresses and workshops should be constantly organized so that medical knowledge is promoted to keep pace with changes in diseases. An organization should determine a measure to periodically inspect and evaluate physicians' moral standards [16].

At an organizational level, patient referral system should be improved together with medical competency development. An organization should determine a model for medical competency development in a form of a clear public policy. Meanwhile, curriculum should be developed in line with the needs of Thai society based on the most diseases suffered by Thai people in each region; then physicians who are excellent at each particular disease should be sent out to provide treatment in such particular region accordingly. Needless to say, there should be a standardized, systematic and accountable process in producing physicians and a committee should be established to monitor and remove disqualified physicians from the system. As a while, there should be a policy encouraging medical teamwork in order to achieve a comprehensive treatment approach and avoid overlapping treatments [17]. A process for physician development should be formulated in a clear policy which is continuously and systematically implemented according to an international standard. Curriculum for physician development should be revised by removing unnecessary subjects and adding general knowledge to broaden their external knowledge.

\subsubsection{Network Development}

Another development approach is to encourage expert physicians to become instructors in order to teach next generations of physicians. The development of medical treatment system should focus on teamwork which includes nurses, medical assistants, equipment and sufficient manpower [18].

\subsubsection{Enabling Environment Development}

Competency development should comprise supplement knowledge of laws, economics and management. Physician competency development should be organized in a way that skills are acquired through on-the-job training, congresses, internet searching and exchange of knowledge among physicians. Besides medical knowledge development, physicians should also learn about external environment by studying any possibilities and changes in society, economy, politics and cultures [19-22]. The government should fully support the work of physicians, such as providing sufficient budget and simultaneously developing medical compe- 
tencies; while appropriate measures must be taken to punish physicians, who make any errors in work [23].

\section{Discussion}

Based on this study, needless to say, medical community is moving to the third generation of revolution, which is called competency-based medical education [16-18]. The competency model is an efficient tool which is designed to evaluate the physicians' qualification, and it will become a significant instrument for the medical education development in the future.

This study systematically constructed physicians' competency model. Research result had revealed that the desirable Thai Medical competencies were consisted with several factors as (1) Medical Knowledge (2) Patient Care (3) Professionalism (4) Systembased Learning (5) Practice-based Learning (6) Interpersonal and Communication Skills. This result was coincident with the work of American Hospital Association on the study on Lifelong Learning Physician competency development that found on as medical knowledge, Patient care, Practice-based learning and improvement, improve patient care practices, Systems-based practice, provide cost-conscious, effective medical care, systems-based practice-Work to promote patient safety, systems-based practice, coordinate care with other health care providers, professionalism, interpersonal \& communication skills-demonstrate, skills that result in effective information exchange, interpersonal \& communication skills, work effectively with health care team and use of informatics. In addition, it has expressed as the development of milestones that define the ACGME and Canada Meds competencies and entrustment-based assessment utilizing the concept of entrustable professional activities (EPAs) have begun to better define this continuum [6-8].

As for Model for Thai Physician Competency Development, it was found that consisting with (1) Individual Development (2) Organizational Development (3) Network Development (4) Enabling Environment Development. This result was coincident with the work of American Hospital Association on the study on Lifelong Learning Physician competency development that stated that hospitals play a vital role in education and training and provide the milieu in which physicians and other clinicians practice. It is essential that hospitals create an environment that fosters the development of and continuously supports the competencies so that they are not an isolated activity, but rather ingrained in every transaction and exchange. In the future, there is a need to set up as the Association of American medical College done as The Physician Competency Reference Set (PCRS) which is a list of common learner expectations utilized in the training of physicians and other health professionals. PCRS will serve as an aggregation tool that allows the AAMC to collect and analyze data through the Curriculum Inventory about competency-based education and the use of expectations (competencies, objectives, milestones, EPAs, etc.) in medical education.

However, comparing the results of this study to those conducted in other countries, it is apparent that the competency model was different, which such different may come from the different conditions and factors. Interestingly, there are a lot of competency which medical community need to add as the work of reflected as Physician skills required for the next generation of health care delivery such as leadership, systems theory and analysis, crossdisciplinary training/multidisciplinary teams, health policy and regulation, time management etc. Such competency has to research in the future.

\section{Conclusion}

The results were shown to be both valid and reliable for measuring physicians' competency in Thailand. The results of the competency-based instrument can be used as of to be the healthcare public policy to encourage and guide regarding healthcare agencies to modify their competency according to the evaluation criteria, and also cultivate physicians with strong knowledge and skills, innovation and redesign the curriculum in medical schools inevitably. Through these measurements and understandings, the overall level of physician's desirable competency will be increased in Thailand.

\section{Acknowledgement}

The study would like to express sincere gratitude to advisor Prof. Dr. Somboon Sirisanhiran for the continuous support of this study and research, the study also would like to thanks to the Thai medical professors and physician from the medical centers, as the indispensable key informants, to dedicate his or her worthy time for the in-depth interview including offering me the summer internship opportunities in their groups and leading me working on diverse exciting projects.

\section{References}

[1] John R. Combes, M. D \& Elisa Arespacochaga. (2012). Physician Competencies for a 21st Century Health Care System J Grad Med Educ., 4(3), 401-405

[2] Morris S., Otto C. N., Golemboski K. (2013). Improving patient safety and healthcare quality in the 21 st century--competencies required of future medical laboratory science practitioners. Clin Lab Sci., Autumn, 26(4), 200-214.

[3] Weinberger S. E. (2011). Providing high-value cost-conscious care: a critical seventh general competency for physicians. Ann Intern Med., 155(6), 386-39.

[4] Lolekha S. Future direction of medical practices in Thailand. Bangkok: Medical Council of Thailand. (2015). http://www.thaihospital .org/board /index.php?topic =2295.0; wap2.

[5] Bodenheimer T., Grumbach K. (1996). Competent Health Care Providers. Understanding Health Policy: A Clinical Approach, 6th Ed. pp. 2-32.

[6] Zipes P. D. (2015). ACC/AHA/HRS Advanced Training Statement on Clinical Cardiac Electrophysiology (A Revision of the ACC/AHA 2006 Update of the Clinical Competence Statement on Invasive Electrophysiology Studies, Catheter Ablation, and Cardioversion). American College of Cardiology Foundation, American Heart Association. Inc, and the Heart Rhythm Society. Elsevier Inc. 2015. 5271(15)01181-9/pdf/

[7] Chitradub S. A (2013). Capacity development system for advisor of children and youth council in Thailand, Full Research report. Office of Promotion and Protection of Children, Youth, the Elderly and Vulnerable Groups. Bangkok: Ministry of Social Development and Human Security;

[8] Mitchell D. Feldman, John F. Christensen, Jason M. Satterfield. (2014). Core Competency for Vulnerable Patients Behavioral Medicine: A Guide for Clinical Practice, 4ed, pp: 12-48.

[9] Wedchayanon N. (2011).Competency Based Approach, School of Public Administration, National Institute of Development Administration. Bangkok: Graphico System, pp. 12-43.

[10] Levinson W., Ginsburg S., Frederic W. Hafferty., Catherine R. Lucey. (2014). Understanding Medical Professionalism. United States of America: McGraw-Hill Education, pp. 33-53.

[11] Mary Ellen, Rick A. Nishimura \& Patrick O'Gara. (2014). Physician Competence: A Perspective from the Practicing Cardiologist Methodist Debakey Cardiovasc J. 10(1), 50-52.

[12] Iglehart J. K., Baron R. B. (2012). Ensuring physicians' competence - is maintenance of certification the answer? N Engl J Med. 27 (26):43-49.

[13] Mosser G., James W. Begun. (2013). Understanding Teamwork in Health Care. 1st ed. New York: LANGE Publishing, pp: 11-34.

[14] Donabedian A. (2000). Evaluating physician competence Bull World Health Organ. 78(6):57-60.

[15] Frank J. R., Snell L. S., et al. (2010). Competency-based medical education: theory to practice. Med Teach, 32:638-645.

[16] Shanafelt T. D. (2012). Burnout and satisfaction with work-life balance among US physicians relative to the general US population. Arch Intern Med., 172 (18): 1377-1385.

[17] Choudhry N. K., Fletcher R. H., Soumerai S. B. (2005). Systematic review: the relationship between clinical experience and quality of health care. Ann Intern Med., 142(4):260-273. 
[18] Cate O, Scheele F. (2007). Competency-based postgraduate training: can we bridge the gap between theory and clinical practice? Acad Med., 82:542-547.

[19] Srikam S. (2013). Job burnout among residents of King Chulalongkorn Memorial Hospital Chulalongkorn University. J Med Assoc Thai., 59(2): 139-50.

[20] Kamarudin, M. K. A., Toriman, M. E., Rosli, M. H., Juahir, H., Aziz, N. A. A., Azid, A., ... \& Sulaiman, W. N. A. (2015). Analysis of meander evolution studies on effect from land use and climate change at the upstream reach of the Pahang River, Malaysia. Mitigation and Adaptation Strategies for Global Change, 20(8), 1319. 1334.

[21] Azid, A., Juahir, H., Toriman, M. E., Endut, A., Rahman, A., Nordin, M., \& Umar, R. (2015). Identification source of variation on regional impact of air quality pattern using chemometric. Aerosol and Air Quality Research, 5, 1545-1558

[22] Toriman, M. E., F. M. Ata, M. K. A. Kamarudin and M. Idris, 2013. Bed-load sediment profile and effect of river bank erosion on river cross-section. Am. J. Environ. Sci., 6, 292-300.

[23] Passi V. (2010). Developing medical professionalism in future doctors: a systematic review. IJME, 1, 19-29. 